\title{
Is reading epilepsy inherited?
}

\author{
A. J. ROWAN, K. W. G. HEATHFIELD, AND D. F. SCOTT \\ From The London Hospital, Whitechapel, London
}

SUMMARY A patient with primary reading epilepsy is reported. Her daughter has major and minor seizures and shows pattern- and photosensitivity. Both have discharges during reading. The implications of these findings are discussed.

Since Bickford and co-workers (1956) first described reading epilepsy other patients with this disorder have been reported by a variety of authors including Stevens (1957) and Critchley, Cobb, and Sears (1960). To our knowledge only Lasater (1962) and Matthews and Wright (1967) have commented specifically on the inheritance of this disorder. We have recently examined a patient with reading epilepsy as well as other family members, and we took the opportunity to investigate the problem of light and pattern sensitivity as well as the electroencephalographic (EEG) abnormalities provoked by reading.

\section{CASE 1}

A 29-year-old right-handed housewife presented with two episodes of loss of consciousness. She was in good health until December 1967 when, after reading a newspaper for a few minutes, she noted jerking movements of her jaw. She felt strange and tried to speak after which she fell forward unconscious. Her husband observed her to have difficulty in breathing, with generalized stiffening followed by rhythmic movements of the extremities. The entire episode lasted less than five minutes and there was no incontinence. On awakening she was confused and did not recognize her husband. Later she regained full awareness and the following morning felt well.

There were no further episodes until May of 1968 when she suffered a similar attack which was preceded by movements of the jaw, again while reading a newspaper.

Further inquiry revealed that the patient had noted jerking jaw movements while reading for at least a year before her first attack. These movements have persisted up to the present time, although they are not invariable in their occurrence. Her reading material includes the local newspaper and occasional novels, but she does not feel that the jaw movements are related to emotional or other particular content of the material. On each occasion the jaw jerks have occurred after only a few minutes of reading. In addition, while reading aloud to her children, she has noticed uncontrollable 'jumping' of spoken words apparently due to unpredictable movements of her jaw.

Her past history was unremarkable; she did not have febrile convulsions in infancy or other previous evidence of a convulsive disorder. She has no siblings and her parents have had no neurological illnesses.

An EEG was performed on the patient who was not receiving anticonvulsant medication. The resting trace was normal as was that during hyperventilation. Lambda waves were provoked when the patient was asked to examine a black and white picture used for this purpose by Groethuysen and Bickford (1956). Photic stimulation produced a following response at low frequencies (1 to 6 flashes per second) and there was no evidence of photosensitivity. Likewise, when patterns consisting of black lines on a white ground were stroboscopically illuminated, whether these lines were horizontally, vertically, or obliquely orientated, no abnormality developed in the EEG. After a latency of two minutes, reading aloud (Fig. 1) produced brief widespread spike/wave episodes particularly well defined post centrally, usually but not always associated with eye movements. Some of the episodes were accompanied by 'jaw jerking' which both the patient and the technician noted; others were not.

\section{CASE 2}

The 8-year-old daughter of case 1 had been well until two and a half years ago when she had a generalized convulsion coincident with high fever. Thereafter she had a number of spells which always occurred while watching television. She would become 'bleary eyed' and unresponsive for several seconds but no movements were noted and there was no incontinence. Of interest is the fact that she usually sat $1 \mathrm{ft}$ away from the television screen. She has had no attacks for the last year since treatment was begun with phenobarbitone and phenytoin coupled with advice to sit at a greater distance from the television screen.

An EEG was performed while the patient was receiving anticonvulsant medication (phenobarbitone $30 \mathrm{mg}$ and phenytoin $100 \mathrm{mg}$, each twice a day). The resting record showed a symmetrical alpha rhythm at about $9 \mathrm{~Hz}$, rendered irregular by an excess of slow activity. Occasional brief generalized symmetrical bursts of high voltage irregular spike/slow wave activity occurred without clinical accompaniment. The repetition rate of the complexes was approximately $3 \frac{1}{2}$ per second. Hyperventilation in- 


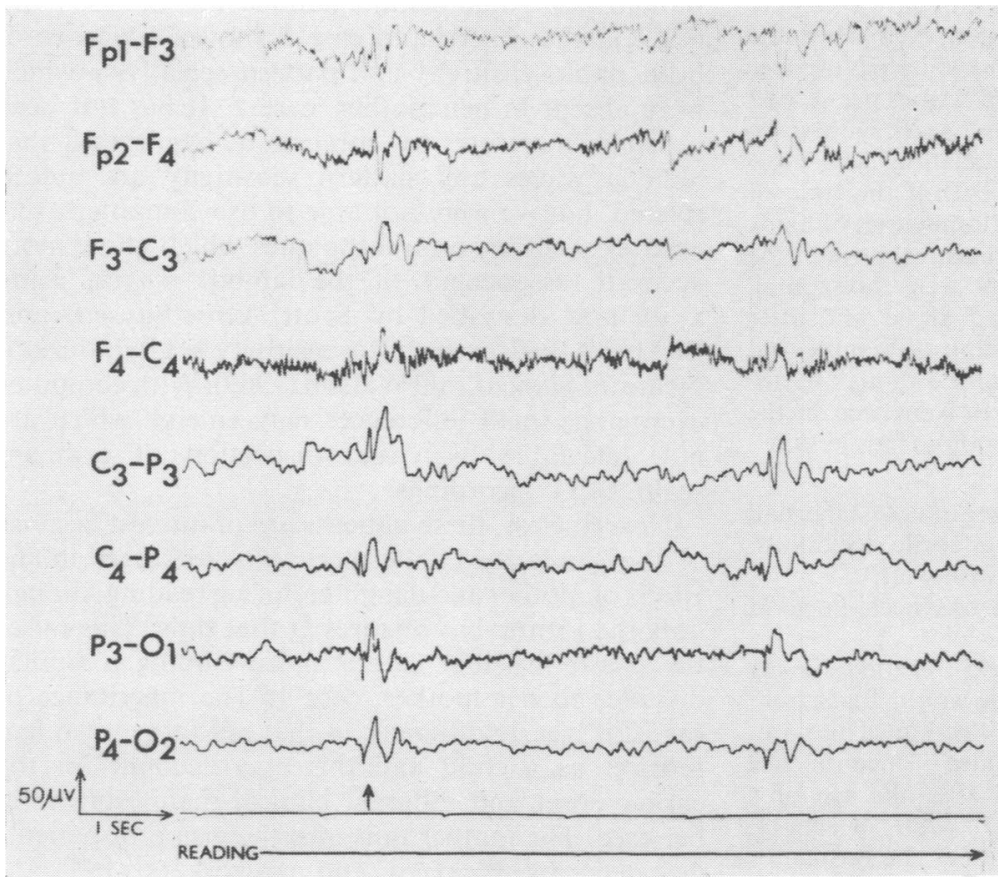

FIG. 1. Electroencephalogram of case 1 during reading; jaw jerk indicated by an arrow.

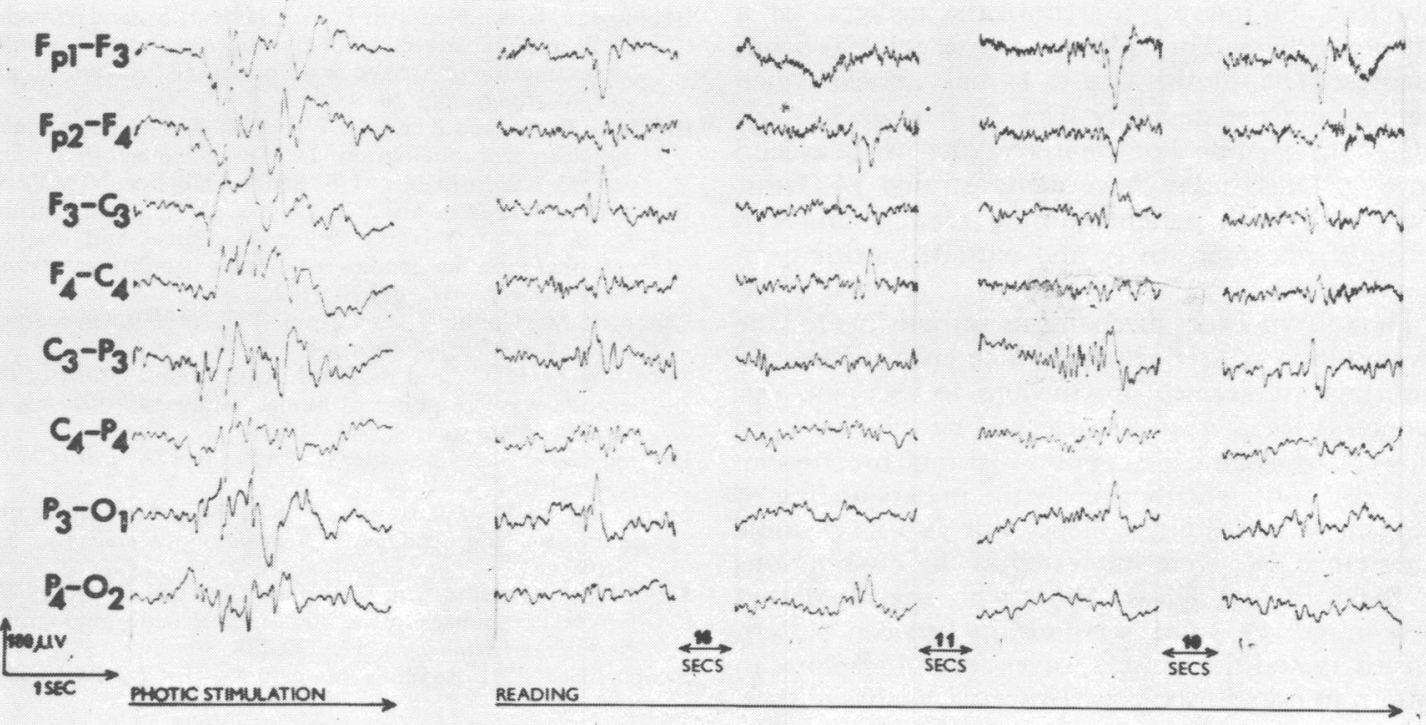

FIG. 2. Electroencephalogram of case 2 during photic stimulation and reading. 
creased the frequency of the bursts. Lambda waves were not observed when the eyes were open even when the patient examined the special black and white picture (see above). Photicstimulation evoked at 18 flashes per second irregular high voltage generalized discharges with spike and multiple spike elements in association with slow waves, These discharges diminished even if the train of flashes was continued. Stroboscopic illumination of black lines on a white ground evoked a similar response to the unpatterned flash whether the lines were horizontal, vertical or oblique. The patient read aloud and after about 55 seconds a discharge consisting of a spike and slow wave was noted. It had a generalized though asymmetrical distribution. Other complexes were seen in the record as reading continued; all were without 'jaw jerking'.

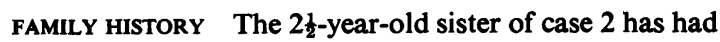
a single tonic seizure coincident with a febrile reaction to measles vaccine. She has been otherwise well.

The 6-year-old brother of case 2 has been in good health without evidence of seizures.

The 32-year-old husband of case 1 recalled having attacks from the ages of 5 to 8 years. He would 'black out', awakening on the floor without recollection of the preceding events. There were a few episodes of incontinence as well. No major attacks occurred after the age of 8 although he recalled 'staring spells' while in school. There was no history of seizures in either the husband's parents or siblings.

\section{DISCUSSION}

Apart from the reports by Lasater (1962) and Matthews and Wright (1967) the inheritance of reading epilepsy has received scant attention. It is, therefore, of interest to report the pedigree of a patient with reading epilepsy whose child also has seizures. The mother (case 1) has attacks when reading and her daughter (case 2) has seizures unrelated to reading but clearly related to television viewing. Our studies have demonstrated EEG discharges in both patients during reading and evidence of photosensitivity and pattern sensitivity in the daughter.

Though the exact mechanisms responsible for the precipitation of seizures in reading epilepsy are still uncertain, it seemed worthwhile to examine our patients with a view to determining whether they showed any electrical responses to stimuli in common, thus not only contributing to the understanding of the genesis of reading epilepsy but also its possible inheritance. We were interested in the observations of Bickford and Klass (1964) who suggested that there might be some relationship between pattern sensitivity and the lambda waves seen in response to pattern in normal subjects. However, we found that, though case 1 had definite lambda waves, case 2 did not. On the other hand case 2 showed evidence of both photosensitivity and pattern sensitivity which were absent in her mother, case 1 . It has not been possible therefore to confirm a hypothesis that lambda waves and pattern sensitivity are indeed related, but we were not able to use computer averaged evoked response techniques which allow more accurate assessment of the lambda waves, using a method described by Scott, Groethuysen, and Bickford (1967) or of photosensitivity, see Bablouzian, Neurath, Sament, and Watson (1969). With computer averaging, small differences may emerge which are not detectable by visual inspection of ordinary scalp EEG recordings.

Nevertheless, these patients are of interest because of the similarity in the electrical discharges in the EEGs of mother and daughter during reading, though only the former has seizures at that time. This raises the possibility that case 2 is developing a similar disorder to her mother, case 1 . The inheritance of case $\mathbf{2}$ is clearly different, in that her father also had seizures as a child and this may account for the earlier onset and different clinical manifestation in her case. The mother falls into the group of patients described by Bickford and co-workers (1956) as suffering from primary reading epilepsy. Her daughter, on the other hand, would seem to be developing secondary reading epilepsy, perhaps suggesting that such a classification may need modification. At present, however, this is a matter for conjecture.

\section{REFERENCES}

Bablouzian, B. L., Neurath, P. W., Sament, S., and Watson, C. W. (1969). Detection of photogenic epilepsy in man by summation of evoked scalp potentials. Electroenceph. clin. Neurophysiol., 26, 93-95.

Bickford, R. G., and Klass, D. W. (1964). Eye movement and the electroencephalogram. In: The Oculomotor System, pp. 293-302. Edited by M. B. Bender. Hoeber: New York.

Bickford, R. G., Whelan, J. L., Klass, D. W., and Corbin, K. B. (1956). Reading epilepsy: clinical and electroencephalographic studies of a new syndrome. Trans. Amer. neurol. Ass., 81, 100-102.

Critchley, M., Cobb, W., and Sears, T. A. (1960). On reading epilepsy. Epilepsia (Amst.), 1, 403-417.

Groethuysen, U. C., and Bickford, R. G. (1956). Study of the lambda-wave response of human beings. Electroenceph. clin. Neurophysiol., 8, 344-345.

Lasater, G. M.: Reading epilepsy (1962). Arch. Neurol.(Chic.), 6, 492-495.

Matthews, W. B., and Wright, F. K. (1967). Hereditary primary reading epilepsy. Neurology (Minneap.), 17, 919-921.

Scott, D. F., Groethuysen, U. C., and Bickford, R. G. (1967). Lambda responses in the human electroencephalogram. Neurology (Minneap.), 17, 770-778.

Stevens, H. (1957). Reading epilepsy. New Engl. J. Med., 257, 165-170. 